IOSR Journal of Pharmacy

e-ISSN: 2250-3013, p-ISSN: 2319-4219, www.iosrphr.org

Volume 2 Issue 6 Nov-Dec. 2012 PP.49-53

\title{
Supplementation of testosterone restores the suppressed fertility in male rats exposed to lead during perinatal period
}

\author{
M. Reshma Anjum ${ }^{1}$ and P. Sreenivasula Reddy ${ }^{2, *}$ \\ ${ }^{1}$ Department of Biotechnology, S.V.University, Tirupati-517502. \\ ${ }^{2}$ Department of Zoology, S.V.University, Tirupati-517502.
}

\begin{abstract}
The objective of the present study was to investigate whether supplementation of testosterone protects suppressed male reproduction in adult rats exposed to lead during perinatal period. Pregnant rats were allocated into three groups. Rats in group I served as controls and animals in group II and III were exposed to ad libitum drinking water containing lead acetate at $0.05 \%$ and $0.15 \%$ throughout their gestational period. All the animals were allowed to deliver pups. Lead exposure was further continued throughout the lactation period (up to 22 days). The male pups from control and lead exposed rats were

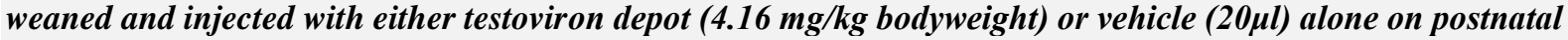
days (PND) 25, 50 and 75. On PND 100, control and experimental males were cohabited with normal cycling 100 day old females for 5 days. Sperm positive females were analyzed to study the male fertility. Significant decrease in the fertility index and mating index in females was observed in females malted with lead exposed male rats. Pre- and post implantation loss was increased significantly in females mated with lead exposed males. Supplementation of testosterone to lead exposed male rats restored all these reproductive parameters.
\end{abstract}

Keywords—Fertility, implantation, lead acetate, perinatal period, rat.

\section{INTRODUCTION}

Incidence of poor male fertility among the population of reproductive age is increasing at an alarming rate and thus, a major concern is oriented towards the protection of male reproductive health $[1,2]$. The reason for reduced fertility is attributed to exposure to several chemicals released into nature. The preponderance of these pollutants, particularly toxic metals is mainly due to anthropogenic life style and rapid industrialization [3].

Lead $(\mathrm{Pb})$ is one of the persistent ubiquitous heavy metals [4] with broad spectrum of toxic effects in animal systems [5,6]. It has been reported that acute or chronic exposure to lead alters testicular functions in humans and wild life [2]. Reproductive consequences of $\mathrm{Pb}$-poisoning are severe and almost all compartments of reproductive system are vulnerable targets to $\mathrm{Pb}$ toxicity [7]. Studies of JP Bonde et al. [8] and N Naha and AR Chowdary [9] suggested that men working in lead based factories showed poor sperm production in terms of quality and density. Several reports suggest that workers exposed to $\mathrm{Pb}$ suffered with oligospermia and astenozoospermia $[10,11]$ with altered sperm morphology [12]. It has also been reported that $\mathrm{Pb}$ toxicity even extends to epididymis and results in altered sperm maturity [13]. AI Aleksandrov et al. [11] reported that presence of $\mathrm{Pb}$ in sperms might be one of the risk factors of male infertility. In addition, studies of NM Biswas and $\mathrm{P}$ Ghosh [14] suggested that a 14-day exposure to $\mathrm{Pb}$-acetate significantly reduces the activity levels of testicular steroidogenic enzymes in rats, which play a key role in the androgen biosynthesis. Thus it appears that, $\mathrm{Pb}$-mediated testicular injury is mainly due to both altered spermatogenesis and sterodiogenesis $[15,16]$.

In both humans and experimental animals, $\mathrm{Pb}$ readily crosses the placental-fetal barrier [17], causing a direct relation between the $\mathrm{Pb}$-exposed mother and the possibility for irreversible developmental damage to her offspring [18]. It is also worth to mention that, in humans, lead is a potential toxicant to infants as it has ability to mobilize from maternal skeleton during lactation. Moreover, studies in humans and experimental animals have shown that not only does $\mathrm{Pb}$ accumulate in the fetus from the second trimester onward [17], but during lactation, it is excreted into the milk, which continues the risk to nursing offspring $[19,20]$. Several studies have reported that gestational administration of lead decreases the fetal and adult hemoglobin synthesis in rats due to the inhibition of enzymatic activities implicated in the hematopoises [21].

It is well established that a circuit of hormones and their interactions in a timely precise manner maintain the structural and functional integrity of male reproductive tract, testosterone being an appreciated hormone [22]. However, the exact interplay between these hormones in relation to male fertility during different stress conditions is unclear. It has been reported that testosterone is a potential candidate in the masculanization 
of reproductive system and also in the maturation process of sperms [23]. Further, adequate levels of androgens are required for the normal sperm shaping and also to attain its fertilizing ability. Studies of PZ Sokol [24] suggested that $\mathrm{Pb}$ toxicity causes disturbances in the hypothalamo-pituitary-testicular (HPT) axis and thereby alters testosterone levels in the circulation. Experiments conducted in our laboratory also suggested that exposure of rats to lead acetate decreases serum testosterone levels with reduced activity levels of testicular steroidogenic enzymes (data not shown). Since, Pb-toxicity mediates testosterone metabolism, the present study was aimed to investigate whether perinatal exposure to lead affects male fertility in adult rats and if so, supplementation of testosterone mitigates lead - induced suppressed male fertility.

\subsection{Animals}

\section{MATERIALS AND METHODS}

Albino rats of Wistar strains obtained from animal breeding colony of the Department of Biotechnology, Sri Venkateswara University, Tirupati were used in the present study. The animals were fed on standard pellet diet (HLL Animal feed, Bangalore, India) and water ad libitum, and maintained under controlled laboratory conditions ( $12 \mathrm{~h}$ light: $12 \mathrm{~h}$ dark; temp. $25 \pm 2^{\circ} \mathrm{C}$; relative humidity $50 \pm 10 \%$ ). Rats were housed in polypropylene cages (four rats per cage) containing sterile paddy husk as bedding material. All the experiments were conducted in accordance with the guidelines for the care and use of laboratory animals [25] and approved by the Institutional Animal Ethical Committee at Sri Venkateswara University, Tirupati, India (Resolution No. 10/(i)/a/CPCSEA/IACE/SVU/PSR-MRA).

\subsection{Test chemicals}

Lead acetate and testoviron depot were used as test chemicals in the present study. Lead acetate of AR grade was procured from E-Merck and testoviron depot which is available in the form of oily solution (Manufactured by German Remedies, India) was purchased from local drug store, Tirupati.

\subsection{Experimental design}

Pregnant rats were allocated into three groups. Rats in group I served as controls and animals in group II and III were exposed to ad libitum drinking water containing lead acetate at $0.05 \%$ and $0.15 \%(273$ and 819 $\mathrm{mg} / \mathrm{L}$ lead) respectively, throughout their pregnancy. All the animals were allowed to deliver pups. Lead exposure was further continued throughout the lactation period (up to 22 days). The F1 generation male rats from control and lead exposed rats were weaned and injected with either testoviron depot $(4.16 \mathrm{mg} / \mathrm{kg}$ bodyweight) or vehicle $(20 \mu \mathrm{l})$ alone on postnatal days (PND) 25, 50 and 75. On PND 100, male rats from control, perinatal lead exposed groups and testosterone injected male rats were housed as breeding pairs (1 male: 1 female) with normal cycling females (100 day old) to be parents of the F2 generation. The cohabitation period was 5 days.

\subsection{Male fertility studies}

F1 generation treated and untreated rats were transferred to a mating cage and cohabited with untreated, 100 day old female rats in proestrus stage (1:1) for 5 days. Animals were checked for the presence of copulatory plugs, and vaginal washings were evaluated for the presence of sperm everyday. The presence of sperm in the vaginal washings was termed as gestation day zero. Sperm positive females were separated from males and some of the pregnant rats were killed $(n=5)$ on $5^{\text {th }}$ day of pregnancy and the remaining pregnant rats $(n=5)$ were killed on $19^{\text {th }}$ day of pregnancy. Both ovaries and the uteri were removed and the number of corpora lutea, implantations and live fetuses was counted. Mating index, fertility index, copulation index, number of embryos per rat, pre-implantation loss (difference between the number of corpora lutea and the number of implantation sites expressed as per number of number of corpora lutea), and post implantation loss (difference between the number of implantation sites and the number of live fetuses expressed as per number of number of implantation sites) was determined. In addition, the conception time, the interval between the first day of cohabitation and the day of vaginal plug and /or sperm in the vaginal fluid was recorded for each female.

\subsection{Statistical analysis}

The data were statistically analyzed using one-way analysis of variance (ANOVA) followed by Dunnet's multiple comparison test. $\mathrm{P}<0.05$ was considered significant. The data were presented as mean \pm S.D. All statistical tests were performed using Statistical Package for Social Sciences (SPSS) version 16.0.

\subsection{General observations}

\section{RESULTS}

No mortality was observed in pregnant rats of control and experimental groups. No signs of clinical toxicity symptoms and/or behavioral abnormalities were observed in rats of all groups.

\subsection{Effect of supplementation of testosterone on fertility studies in perinatal lead exposed F1 male rats}

Sexual motivation is the primary response of male rats as soon as the female was introduced into the mating cage. In the present study, the rats in control and experimental groups exhibited signs of sexual 
motivation like licking the female genitalia, chasing the female, passing under each other's body and attempting to mount the female as soon as the female was introduced.

Lead exposed rats administered with testosterone took less conception time to impregnate females. Marginal increase in number of implantations and decrease in pre- and post-implantation loss in females mated with rats co-administered with lead and testosterone indicating increased fertility efficiency. However, no significant fertility improvement was observed in normal rats injected with testosterone alone when compared with that of control rats (Table 1).

Table 1: Effect of testosterone ( $\mathrm{T})$ on male reproductive performance in adult male rats exposed to lead $(\mathrm{Pb})$ during perinatal period

\begin{tabular}{|c|c|c|c|c|c|c|}
\hline \multirow[t]{3}{*}{ Parameter } & \multirow{2}{*}{\multicolumn{2}{|c|}{ Control }} & \multicolumn{4}{|c|}{ Lead $(\mathrm{Pb})$ exposed rats } \\
\hline & & & \multicolumn{2}{|c|}{$0.05 \%$} & \multicolumn{2}{|l|}{$0.15 \%$} \\
\hline & C & $\mathrm{C}+\mathrm{T}$ & $\mathbf{P b}$ & $\mathbf{P b}+\mathbf{T}$ & $\mathbf{P b}$ & $\mathbf{P b}+\mathbf{T}$ \\
\hline $\begin{array}{l}\text { Conception time } \\
\text { (days) }\end{array}$ & $1.2^{\mathrm{a}} \pm 0.78$ & $\begin{array}{c}1.3^{\mathrm{a}} \pm 0.63 \\
(8.33)\end{array}$ & $\begin{array}{c}3.9^{\mathrm{b}} \pm 0.07 \\
(225)\end{array}$ & $\begin{array}{c}2.2^{\mathrm{c}} \pm 0.18 \\
(-43.5)\end{array}$ & $\begin{array}{c}4.7^{\mathrm{d}} \pm 0.31 \\
(291.6)\end{array}$ & $\begin{array}{c}2.9^{\mathrm{e}} \pm 0.21 \\
(-38.29)\end{array}$ \\
\hline $\begin{array}{l}\text { Copulation index } \\
(\%)\end{array}$ & $100(10 / 10)$ & $100(10 / 10)$ & $80(8 / 10)$ & $90(9 / 10)$ & $80(8 / 10)$ & $90(9 / 10)$ \\
\hline $\begin{array}{l}\text { Fertility index } \\
(\%)\end{array}$ & $100(10 / 10)$ & $100(10 / 10)$ & $100(8 / 8)$ & $100(9 / 9)$ & $100(8 / 8)$ & 100(9/9) \\
\hline $\begin{array}{l}\text { Number of } \\
\text { corpora lutea } / \mathrm{rat}^{*}\end{array}$ & $14.01^{\mathrm{a}} \pm 0.89$ & $\begin{array}{c}13.16^{\mathrm{a}} \pm 0.7 \\
(-6.0)\end{array}$ & $\begin{array}{c}13.5^{\mathrm{a}} \pm 1.5 \\
(-3.57)\end{array}$ & $\begin{array}{c}13.33^{\mathrm{a}} \pm 1.5 \\
(-1.25)\end{array}$ & $\begin{array}{c}13.5^{\mathrm{a}} \pm 1.06 \\
(-3.57)\end{array}$ & $\begin{array}{l}13.88^{\mathrm{a}} \pm 1.5 \\
(2.81)\end{array}$ \\
\hline $\begin{array}{l}\text { Number of } \\
\text { implantations/rat* }\end{array}$ & $12.66^{\mathrm{a}} \pm 1.52$ & $\begin{array}{c}11.83^{\mathrm{a}} \pm 0.4 \\
(-6.55)\end{array}$ & $\begin{array}{c}10.6^{\mathrm{a}} \pm 1.1 \\
(-16.27)\end{array}$ & $\begin{array}{c}12.1^{\mathrm{a}} \pm 1.8 \\
(14.15)\end{array}$ & $\begin{array}{c}7.75^{\mathrm{b}} \pm 2.3 \\
(-38.78)\end{array}$ & $\begin{array}{c}10.2^{\mathrm{a}} \pm 1.6 \\
(31.61)\end{array}$ \\
\hline $\begin{array}{l}\text { Pre-implantaion } \\
\text { loss }(\%)\end{array}$ & 9.52 & 11.27 & 21.48 & 2.7 & 42.59 & 27.99 \\
\hline $\begin{array}{l}\text { Number of live } \\
\text { pups/rat }\end{array}$ & $11.71^{\mathrm{a}} \pm 0.51$ & $\begin{array}{c}10.5^{\mathrm{a}} \pm 1.05 \\
(-10.33)\end{array}$ & $\begin{array}{c}8.37^{\mathrm{b}} \pm 0.54 \\
(-28.52)\end{array}$ & $\begin{array}{c}11.12^{\mathrm{a}} \pm 0.91 \\
(32.85)\end{array}$ & $\begin{array}{c}5.12^{\mathrm{c}} \pm 0.72 \\
(-56.27)\end{array}$ & $\begin{array}{c}10.21^{\mathrm{a}} \pm 0.63 \\
(99.41)\end{array}$ \\
\hline $\begin{array}{l}\text { Number of } \\
\text { resorptions }\end{array}$ & - & - & - & -- & 1 & -- \\
\hline $\begin{array}{l}\text { Post-implantaion } \\
\text { loss }(\%)\end{array}$ & 7.52 & 11.24 & 21.03 & 8.09 & 33.93 & 7.9 \\
\hline
\end{tabular}

Values are given as mean \pm S.D of ten individuals

Mean values that do not share same superscript differ significantly from each other at $\mathrm{p}<0.05$

Values in the parentheses are percent change from that of control

For calculation of percent change for $\mathrm{C}+\mathrm{T}$ group, lead exposed groups $(0.05 \%$ or $0.15 \%)$ untreated rats served as controls; for $\mathrm{Pb}+\mathrm{T}$ treated groups respective $\mathrm{Pb}$ exposed rats served as controls.

\section{DISCUSSION}

It has been reported that chronic exposure to lead have been associated with increased incidences of still birth, reduced litter size, growth retardation and neonatal death rates [26]. Studies of I Corpas et al. [27] suggested that perinatal exposure to lead intoxication targets male reproductive system in addition to its primary neurotoxic effects.

Several andrological studies suggested adverse reproductive effects in males might at least, in part, stem from fetal exposure of the developing male to a range of endocrine disruptors [28,29]. Further, studies also demonstrated that alterations in the gonadal hormones affects the sexual differentiation of the brain [30] and several aspects of differentiation can also be influenced during this period such as adult sensitivity to the activating effects of sex steroids on behaviors [31], and long-term regulation of gonadotropin secretion [32]. It seems apparent that development of male fetus is primarily influenced by hormones and perhaps any disturbances at this period eventually results in abnormal male function(s) later. The most interesting finding of the present study was that reduction in the fertility in male rats exposed to lead during perinatal period. In general, prenatal stress has been suggested to induce inappropriate levels of testosterone and aromatase activity in male rat fetuses during the critical stages of sexual differentiation (i.e., from 18-19 days of gestation), thus resulting in abnormal copulatory behaviour and high rates of female lordotic response in male offspring [33,34].

In the present study, the sexual behavior is not affected in lead exposed rats. Exposure to lead acetate during perinatal period resulted in a decrease in fertility index at adulthood. Perinatal lead exposed male rats were able to impregnate female rats but comparatively in less number. The observed decrease in fertility in males has been attributed to a decrease in testosterone levels in circulation resulting in decrease in sperm quality 
and density (author's unpublished data). The increase in pre-implantation loss observed in the present study may be at least in part due to failure of fertilization due to poor sperm quality and lowered sperm density. Thus, the results of the present study indicate that lead acetate exposure during perinatal period will affect the reproductive potential at adulthood in rats. In females cohabited with testosterone treated lead exposed rats, pre and post-implantation loss were reduced over rats cohabited with perinatal lead alone exposed rats. This indicates that testosterone improves the fertility efficiency in lead exposed rats.

From the results, it is evident that the reduced reproductive performance by the perinatal exposure to lead acetate may be due to decreased steroidogenesis and spermatogenesis. The inferior sperm quality and low sperm density might be responsible for suppressed reproductive performance in the perinatal lead exposed rats. Therefore, the present study indicates that sufficiently high lead intake through drinking water during pregnancy and lactation may pose a danger to the male reproduction in adult stage by affecting both steroidogenesis and spermatogenesis. Further, the studies also demonstrate that testosterone administration ameliorates the deteriorated reproductive health in male rats exposed to lead during their perinatal period.

\section{ACKNOWLEDGEMENTS}

The authors are grateful to the Head, Department of Biotechnology, S.V. University, Tirupati for providing facilities. One of the authors (PSR) is thankful to University Grant Commission, New Delhi [(F.No. 32-502/2006(SR)] and Indian Council of Medical Research, New Delhi for providing financial assistance. We thank Prof. K.V.S. Sarma for the statistical analysis of data and Mr S. Umasankar for maintaining rat colony. The authors declare that the experiments conducted during these studies comply with the current laws of their country.

\section{REFERENCES}

[1]. C. Castellini, E. Mourvaki, B. Sartini, R. Cardinali, E. Moretti, G. Collodel, S. Fortaner, E. Sabbioni, T. Renieri, In vitro toxic effects of metal compounds on kinetic traits and ultrastructure of rabbit spermatozoa. Reprod. Toxicol, 27, 2009, 46-54.

[2]. JD. Meeker, L. Godfrey-Bailey, R. Hauser, Relationships between serum hormone levels and semen quality among men from an infertility clinic. J. Androl, 28, 2007, 397-406.

[3]. IJ. Fisher, DJ. Pain, VG. Thomas, A review of lead poisoning from ammunition sources in terrestrial birds. J. Biol. Conser, 131, 2006, 421-432.

[4]. M. Helberg, JO. Bustnes, KE. Erikstad, KO. Kristiansen, JU. Skaare, Relationships between reproductive performance and organochlorine contaminants in great blackbacked gulls (Larus marinus). Environ. Pollution, $134,2005,475-483$.

[5]. JM. Fair, RE. Ricklefs, Physiological, growth, and immune responses of Japanese quail chicks to the multiple stressors of immunological challenge and lead shot. Arch. Environ. Contam. Toxicol, 42, 2002, 77-87.

[6]. T. Snoeijs, T. Dauwe, R. Pinxten, F. Vandesande, M. Eens, Heavy metal exposure affects the humoral immune response in a free-living small songbird, the great tit (Parus major). Arch. Environ. Contam. Toxicol, 46, 2004, 399-404.

[7]. M. Marchlewicz, B. Wiszniewska, B. Gonet, I. Baranowska-Bosiacka, K. Safranow, A. Kolasa, W. Glabowski, R. Kurzawa, K. Jakubowska, ME. Rac, Increased lipid peroxidation and ascorbic acid utilization in testis and epididymis of rats chronically exposed to lead. BioMetals, 20, 2007, 13-19.

[8]. JP. Bonde, M. Joffe, P. Apostoli, A. Dale, P. Kiss, M. Spano, F. Caruso, A. Giwercman, L. Bisanti, S. Porru, M. Vanhoorne, F. Comhaire, W. Zschiesche, Sperm count and chromatin structure in men exposed to inorganic lead: lowest adverse effect levels. Occup. Environ. Med, 59, 2002, 234-242.

[9]. N. Naha, AR. Chowdary, Toxic effect of lead on human spermatozoa: a study among pigment factory workers. Int. J. Occup. Environ. Med, 9, 2005, 118-123.

[10]. RP. Gennart, JP. Buchet, H. Roels, P. Ghyselen, E. Ceulemans, R. Lauwerys, Fertility of male workers exposed to cadmium, lead or manganese. Am. J. Epidemiol, 135, 1992, 1208-1219.

[11]. AI. Aleksandrov, AI. Prokofev, NN. Bubnov, Stabilization of metal ions in unusual oxidation states and electron dynamics in oxide glasses. Russ. Chem. Rev, 65, 1996, 479-496.

[12]. AR. Chowdhury, Recent advances in heavy metals induced effect on male reproductive function-A retrospective. Al Ameen J. Med. Sci, 2, 2009, 37-42.

[13]. SC. Sikka, Oxidative stress and role of antioxidants in normal and abnormal sperm function. Front. Biosci, 1, 1996, 78-86.

[14]. NM. Biswas, P. Ghosh, Effects of lead on gonadal activity in albinos rats. Kathmandu University Med, 2, 2004, 43-46.

[15]. J. Singh, C. Oneill, DJ. Handelsman, Induction of spermatogenesis by androgens in gonadotropin-deficient (Hpg) mice. Endocrinology, 136, 1995, 5311-5321.

[16]. P. Hsu, M. Liu, C. Hsu, L. Chen, Y. Guo, Lead exposure causes generation of reactive oxygen species and functional impairment in the rat sperm. Toxicology, 122, 1997, 133-143.

[17]. RA. Goyer, Transplacental transport of lead. Environ. Health Perspect, 89, 1990, 101-105.

[18]. WN. Rom, Effects of lead on the female and reproduction: a review. Mt. Seinai J. Med, 43, 1976, 542-552. 
[19]. D. Namihira, L. Saldivar, N. Pustilnik, GJ. Carreon, ME. Salinas, Lead in human blood and milk from nursing women living near a smelter in Mexico City. J. Toxicol. Environ. Health, 38, 1993, 225-232.

[20]. IP. Hallen, L. Jorhem, BJ. Lagerkvist, A. Oskarsson, Lead and cadmium levels in human milk and blood. Sci. Total Environ, 166, 1995, 149-155.

[21]. CN. Ong, WR. Lee, High affinity of lead for fetal haemoglobin. Br. J. Int. Med, 37, 1980, 292-298.

[22]. T. Mann, Secretary function of the prostate, seminal vesicle, and other male accessory organs of testis. Andrologia, 52, 1974, 12-17.

[23]. B. Robaire, S. Seenundun, M. Hamzeh, S. Lamour, Androgenic regulation of novel genes in the epididymis. Asian J. Androl, 9, 2007, 545-553.

[24]. PZ. Sokol, Hormonal effects of lead acetate in the male rat: mechanism of action. J. Biol. Reprod, 37, 1987, 11351138.

[25]. National Research Council, Guide of the Care and Use of Laboratory Animals. National Academy Press, Washington, DC p.125, 1996.

[26]. I. Baranowska, Lead and cadmium in human placentas and maternal and neonatal blood in a heavily polluted area measured by graphite furnace atomic absorption spectrometry. Occup. Environ. Med, 52, 1995, 229-232.

[27]. I. Corpas, M. Castillo, D. Marquina, MJ. Benito, Lead intoxication in gestational and lactational periods alters the development of male reproductive organs. Ecotoxicol. Environ. Safety, 53, 2002, 259-266.

[28]. NE. Skakkebaek, E. Rajpert-De Meyts, KM. Main, Testicular dysgenesis syndrome: an increasingly common developmental disorder with environmental aspects. Hum. Reprod, 16, 2001, 972-978.

[29]. JS. Fisher, S. Macpherson, N. Marchetti, RM. Sharpe, Human testicular dysgenesis syndrome: a possible model using in utero exposure of the rat to dibutyl phthalate. Hum. Reprod, 18, 2003, 1383-1394.

[30]. BS. McEwen, Steroid hormones: Effect on brain development and function. Horm. Res, 37, 1992, 1-10.

[31]. WW. Beatty, Gonadal hormones and sex differences in nonreproductive behavior in rodents: Organizational and activational effects. Horm. Behav, 12, 1979, 112-163.

[32]. RJ. Handa, RF. McGivern, EP. Noble, RA. Gorski, Exposure to alcohol in utero alters the adult pattern of luteinizing hormone secretion in male and female rats. Life Sci, 37, 1985, 1683-1690.

[33]. IL. Ward, Prenatal stress feminizes and demasculinizes the behavior of males. Science, 175, 1972, 82-84.

[34]. LV. Osadchuk, BO. Braastad, I. Huhtaniemi, M. Bakken, Alterations of the pituitary-gonadal axis in the neonatal blue fox (Alopex lagopus) exposed to prenatal handling stress. Reprod. Fertil. Dev, 12, 2000, 119-126. 